\title{
Principles of diagnosis and management of neuroendocrine tumours
}

\author{
Michael J. Raphael MD, David L. Chan MBBS, Calvin Law MD, Simron Singh MD
}

Cite as: CMAJ 2017 March 13;189:E398-404. doi: 10.1503/cmaj.160771

$\mathbf{N}$ euroendocrine tumours (NETs) are a unique group of malignant growths, best known for their ability to secrete bioactive peptides, which may cause symptoms such as flushing and diarrhea. Although NETs traditionally have been considered uncommon, a recent population-based study reported that the incidence of NETs in Canada had risen markedly from 2.48 to 5.86 per 100000 per year between 1994 and 2009. ${ }^{1}$ For reference, the incidence of NETs is now similar to that of cervical cancer according to the most recent Canadian Cancer Society statistics. ${ }^{2}$

Because NETs are perceived to be uncommon and may be nonspecific in their presentation, delays in diagnosis are frequent. A recent international survey of 1928 patients with NETs reported a mean delay of 52 months between symptom onset and diagnosis; patients see an average of six different health care providers before receiving the correct diagnosis. ${ }^{3}$ Unfortunately, when patients are ultimately diagnosed with a NET, many will have metastases; population-based studies have reported that $21 \%$ of patients are found to have metastases at the time of diagnosis, ${ }^{1,4}$ whereas proportions as high as $56 \%-69 \%$ have been reported in retrospective chart reviews. ${ }^{5,6}$

This review summarizes the classification, presentation, diagnostic workup and treatment of NETs with the aim of helping generalists to facilitate timely diagnosis and referral. Diagnostic recommendations made in this review are based on consensus expert opinion, whereas recommendations for systemic treatment are largely based on phase three randomized controlled trials (RCTs), which compare new treatments with standard treatment. All recommendations are consistent with current Canadian national guidelines. ${ }^{7,8}$ Box 1 summarizes the evidence supporting this review.

\section{What are neuroendocrine tumours?}

Neuroendocrine tumours are malignant growths that arise from neuroendocrine cells. They most commonly occur in the gastrointestinal tract (48\%), lung (25\%) and pancreas (9\%), but may also develop in many other organs, including the breast, prostate, thymus and skin. ${ }^{1}$ Neuroendocrine cells have the capability to produce hormones, such as serotonin, ${ }^{9}$ which can result in symptoms such as flushing and diarrhea, as well as other proteins (e.g., chromo-

\section{KEY POINTS}

- Neuroendocrine tumours are increasing in both incidence and prevalence in Canada.

- Most patients present with non-specific symptoms such as cough, abdominal pain, bloating and weight loss; few patients present with all features of the classical carcinoid syndrome characterized by flushing, diarrhea and valvular heart disease.

- Clinicians should have a high index of suspicion to ensure timely diagnosis and referral to multidisciplinary subspecialty centres.

- Treatment options are rapidly expanding and many patients with neuroendocrine tumours may have extended survival periods with well-controlled symptoms and a better quality of life.

granin A), which serve as biomarkers for NETs. ${ }^{10-12}$ Neuroendocrine tissues also tend to express somatostatin receptors on their cell surfaces. Therefore, somatostatin analogues can be useful for diagnostic imaging and treatment. ${ }^{13,14}$

\section{How are neuroendocrine tumours classified?}

There are three clinicopathologic features that drive the biological behaviour of NETs: grade, differentiation and stage.

\section{Grade}

Histologic grade reflects the biological aggressiveness of the neoplasm. There are two main features of grade: the Ki67 index, which measures the percentage of cancer cells that stain positive for Ki67, a marker of cell proliferation (Figure 1) and the mitotic rate, which documents the number of mitoses per 10 high-power microscopic fields. ${ }^{15-17}$ The Canadian National Expert Group on NETs recently endorsed the grading system from the World Health Organization (Table 1). ${ }^{7,8,18,19}$ The importance of accurate grade cannot be overemphasized as it is the key determinant of prognosis. ${ }^{4,7,8}$ Based on data from the Surveillance, Epidemiology and End Results (SEER) Program (United States National Cancer Institute) database, the median survival for patients with a grade 1,2 or 3 tumour is 124 months, 64 months and 10 months, respectively. ${ }^{4}$ 


\section{Box 1: Evidence used in this review}

We searched MEDLINE, Embase, Google Scholar and the Cochrane Database of Systemic Reviews for articles relating to the diagnosis, classification and management of neuroendocrine tumours. Search terms included "neuroendocrine tumors," "neuroendocrine neoplasms," "carcinoid tumors," "islet cell tumors" and

"bronchopulmonary neuroendocrine tumors." We then searched for abstracts from major international oncology conferences to identify any recently completed studies. The reference lists of all relevant articles were reviewed for studies not captured in the original search.

\section{Differentiation}

Differentiation refers to how closely the neoplastic cells resemble their nonneoplastic counterparts in the tissue from which they arose. Well-differentiated cancer cells closely resemble nonneoplastic cells, whereas poorly differentiated cancer cells do not. In general, lowgrade tumours (grades 1 and 2 ) are well-differentiated and highgrade tumours (grade 3 ) are poorly differentiated. ${ }^{15}$

\section{Stage}

Stage refers to extent of tumour spread throughout the body and, as for other cancers, the Tumor Node Metastasis (TNM) system is used. The Canadian National Expert Group on NETs recently endorsed the staging groupings described in the 7th edition of the American Joint Committee on Cancer Staging Manual. ${ }^{7,8,21}$ However, for practical purposes, NETs can be considered as either early stage (completely resectable) or advanced stage (either locally advanced and unresectable or metastatic).

\section{Nomenclature}

The German pathologist Sigfried Oberndorfer coined the term "Karzinoide" in 1907, meaning carcinoma-like, to describe small benign-appearing tumours of the small intestine. ${ }^{22}$

The term "carcinoid" is no longer recommended, because it fails to convey the malignant potential that most NETs harbour. The term is also confusing, because it promotes the misconception that all NETs produce the carcinoid syndrome, when most do not. ${ }^{5,6,23-26}$ Currently, the term "neuroendocrine tumour" is preferred to describe grade 1 and 2 tumours, whereas the term "neuroendocrine carcinoma" is used to describe grade 3 tumours.

\section{How do neuroendocrine tumours present?}

Neuroendocrine tumours may be found as an incidental finding or may be suspected from clinical symptoms. When NETs cause clinical symptoms from secreted hormones, they are termed "functioning" (Table 2). Most NETs do not produce a biologically active hormone and are termed "nonfunctioning." "5,6,23-26 Both functioning and nonfunctioning NETs tend to present late with nonspecific symptoms that are often attributed to an alternative diagnosis (Table 3). In the aforementioned international survey of patients with confirmed NETs, the most common initial diagnoses provided to patients included gastritis, irritable bowel syndrome, anxiety, inflammatory bowel disease, asthma and menopause. ${ }^{3}$

Some symptoms may suggest the diagnosis and location of a NET. Small intestinal NETs may cause extensive fibrosis, which result in recurrent abdominal pain secondary to small bowel obstruction or mesenteric ischemia. In a retrospective study of 121 consecutive patients with midgut NETs who underwent surgical resection, marked mesenteric fibrosis and intestinal ischemia were found in $65 \%$ and $38 \%$ of patients, respectively. ${ }^{28}$ Bronchopulmonary NETs tend to present with centrally located lesions that may result in bronchial obstruction, recurrent obstructive pneumonitis, cough and hemoptysis. ${ }^{24-26}$ Furthermore, bronchopulmonary NETs may be a source of ectopic adrenocorticotrophic hormone (ACTH) production; clinicians should consider this diagnosis in otherwise unexplained Cushing syndrome..$^{25,29-31}$

\section{Carcinoid syndrome}

Carcinoid syndrome, characterized by flushing, diarrhea and valvular heart disease, occurs when hormones produced by NETs reach systemic circulation. This happens most commonly after liver metastases develop, allowing for bypass of hepatic metabolism that may inactivate the hormones. Retrospective cohort studies report that carcinoid syndrome occurs in $6 \%-13 \%$ of patients with pathologically confirmed gastrointestinal NETs and in less than $1 \%$ of patients with bronchopulmonary NETs..$^{24,25,32-34}$ Hindgut tumours (distal colon and rectum) are typically hormonally silent and do not cause carcinoid syndrome. ${ }^{34}$

Valvular heart disease secondary to fibrotic plaques has been reported in $8 \%-56 \%$ of patients with carcinoid syndrome in retrospective cohort studies. ${ }^{23,35-37}$ Because $43 \%$ of patients in these stud-

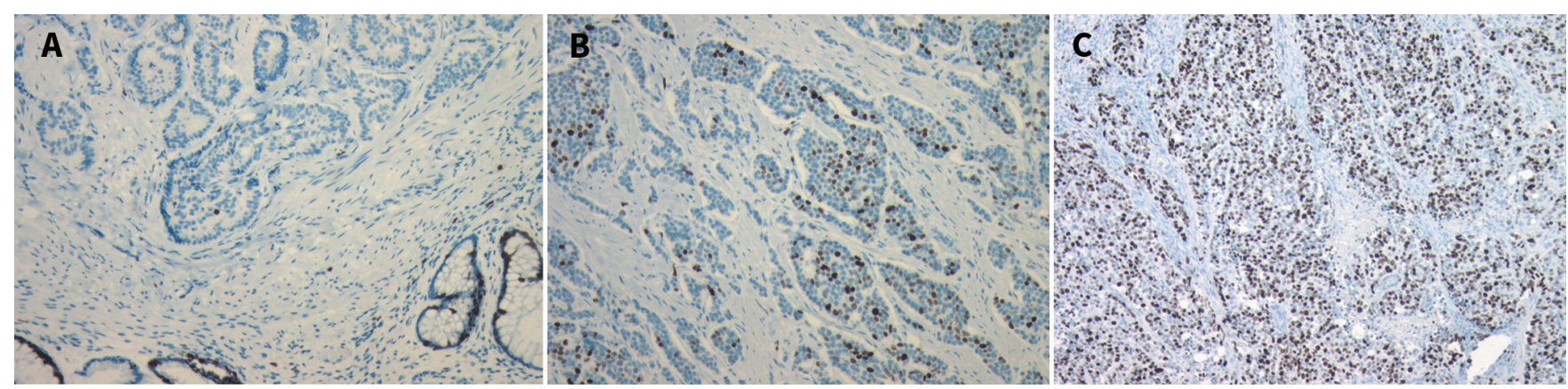

Figure 1: Pathology specimens of tissue from a neuroendicrine tumour with staining for Ki67 (a nuclear protein involved with cell proliferation). MIB-1 is an immunoglobulin $\mathrm{G}(\mathrm{IgG})$ antibody directed against Ki67 that can be used to identify the percentage of cells undergoing active cell proliferation. (A) Ki67 index <3\%. (B) Ki67 index 3\%-20\%. (C) Ki67 index > 20\%. Images provided by Dr. Corwyn Rowsell (St. Michael's Hospital, Department of Laboratory Medicine and Pathobiology, University of Toronto, Toronto, Ont.). 
ies were asymptomatic, screening echocardiography in this group is important to allow timely intervention of valvular disease. ${ }^{36}$

Carcinoid crisis is an acute life-threatening presentation of carcinoid syndrome characterized by profound flushing, bronchospasm and rapidly fluctuating blood pressure. It may be precipitated by induction of anesthesia or palpation, ablation or embolization of a NET. ${ }^{38}$ Therefore, patients should be given a somatostatin analogue before any anesthetic or tumour manipulation.,

\section{How are neuroendocrine tumours diagnosed?}

The diagnosis of a NET requires a coordinated multidisciplinary effort involving medical oncologists, surgeons, interventional radiologists and pathologists. Results from pathology testing, hormonal testing, and diagnostic and functional imaging are integrated to form a comprehensive diagnostic picture.

\section{Table 1: World Health Organization grading systems for neuroendocrine tumour ${ }^{18-20}$}

\section{NET of the lung and thymus}

\begin{tabular}{|c|c|c|c|c|}
\hline Grade & Nomenclature & Proliferative rate & Nomenclature & Proliferative rate \\
\hline Low (Grade 1) & Typical carcinoid & $\begin{array}{l}<2 \text { mitoses/10 hpf AND } \\
\text { no necrosis }\end{array}$ & NET/pNET & $\begin{array}{l}<2 \text { mitoses } / 10 \text { hpf AND } \\
<3 \% \text { Ki67 index }\end{array}$ \\
\hline $\begin{array}{l}\text { Intermediate } \\
\text { (Grade 2) }\end{array}$ & Atypical carcinoid & $\begin{array}{l}2-10 \text { mitoses } / 10 \mathrm{hpf} \text { OR } \\
\text { foci of necrosis }\end{array}$ & & $\begin{array}{l}2-20 \text { mitoses } / 10 \mathrm{hpf} \text { OR } \\
3 \%-20 \% \text { Ki67 index }\end{array}$ \\
\hline High (Grade 3) & $\begin{array}{l}\text { Small cell lung cancer, large } \\
\text { cell neuroendocrine } \\
\text { carcinoma }\end{array}$ & $>10$ mitoses $/ 10 \mathrm{hpf}$ & $\begin{array}{l}\text { Neuroendocrine } \\
\text { carcinoma }\end{array}$ & $\begin{array}{l}>20 \text { mitoses } / 10 \text { hpf OR } \\
>20 \% \text { Ki67 index }\end{array}$ \\
\hline
\end{tabular}

Note: $\mathrm{hpf}=$ high powered field, NET = neuroendocrine tumour, pNET = pancreatic neuroendocrine tumour. The nomenclature for NETs varies by site. Per the World Health Organization grading system, low- and intermediate-grade tumours in the lung are still called typical carcinoid and atypical carcinoid, respectively; high-grade NETs in the lung are either small cell lung cancer or large cell neuroendocrine carcinoma. In the gastrointestinal tract, low- and intermediate-grade tumours are called NETs, whereas in the pancreas they are called PNETs. High-grade gastroenteropancreatic tumours are called neuroendocrine carcinomas rather than NETs.

\section{Table 2: Functional neuroendocrine tumour syndromes ${ }^{24-27}$}

\begin{tabular}{|c|c|c|c|c|}
\hline Tumour & $\begin{array}{l}\text { Tumour } \\
\text { location }\end{array}$ & Hormone & Symptoms and signs & Syndrome \\
\hline Atypical carcinoid & Foregut & 5-HTP, histamine & $\begin{array}{l}\text { Pruritus, cutaneous wheals, } \\
\text { bronchospasm }\end{array}$ & Atypical carcinoid \\
\hline Carcinoid & $\begin{array}{l}\text { Small intestine, } \\
\text { lung }(<5 \%)^{*} \\
\text { pancreas }(<1 \%)^{\star}\end{array}$ & $\begin{array}{l}\text { Serotonin, } \\
\text { tachykinin, } \\
\text { prostaglandins }\end{array}$ & $\begin{array}{l}\text { Flushing, diarrhea, valvular } \\
\text { disease, bronchospasm }\end{array}$ & Carcinoid \\
\hline Insulinoma & $\begin{array}{l}\text { Pancreatic } \beta \\
\text { cells }\end{array}$ & $\begin{array}{l}\text { Insulin, } \\
\text { proinsulin }\end{array}$ & Hypoglycemic symptoms & Whipple triad \\
\hline Gastrinoma & $\begin{array}{l}\text { Gastrinoma } \\
\text { triangle† }\end{array}$ & Gastrin & Diarrhea, peptic ulcer disease & Zollinger-Ellison \\
\hline Glucagonoma & $\begin{array}{l}\text { Pancreatic } a \\
\text { cells }\end{array}$ & Glucagon & $\begin{array}{l}\text { Diabetes, deep vein thrombosis, } \\
\text { depression, dermatitis (necrolytic } \\
\text { migratory erythema) }\end{array}$ & 4D syndrome \\
\hline Somatostatinoma & $\begin{array}{l}\text { Pancreatic } \delta \\
\text { cells }\end{array}$ & Somatostatin & $\begin{array}{l}\text { Diabetes, cholelithiasis, steatorrhea, } \\
\text { weight loss, achlorhydria }\end{array}$ & Somatostatinoma \\
\hline VIPoma & Non- $\beta$ islet cells & $\begin{array}{l}\text { Vasoactive } \\
\text { intestinal peptide }\end{array}$ & $\begin{array}{l}\text { Watery diarrhea (profuse), } \\
\text { hypokalemia, achlorhydria }\end{array}$ & $\begin{array}{l}\text { Verner-Morrison } \\
\text { (WDHA syndrome) }\end{array}$ \\
\hline ACTHoma & Lung $(4 \%)^{*}$ & АСТH & $\begin{array}{l}\text { Fat redistribution/obesity, facial } \\
\text { plethora, skin atrophy/easy } \\
\text { bruising/striae, proximal } \\
\text { myopathy, hyperglycemia }\end{array}$ & Cushing syndrome \\
\hline
\end{tabular}




\section{Pathology}

Obtaining tissue for pathology testing is mandatory for the diagnosis of NETs. When surgical resection is not an option, core needle biopsy is preferred over fine needle aspiration to allow full assessment of the tumour architecture. ${ }^{7,8}$

\section{Syndrome-specific biochemical testing}

For patients presenting with symptoms of a functioning NET, biochemical testing should be targeted to the specific syndrome (Table 2). For patients presenting with a small intestinal mass or with features of carcinoid syndrome, a 24-hour urine 5-hydroxyindole acetic acid (5-HIAA) test should be ordered. This test has a reported sensitivity of $35 \%-73 \%{ }^{12,39,40}$ Patients must refrain from eating serotoninrich foods (e.g., bananas, pineapples, avocados, kiwi fruits or nuts) for at least three days before testing to prevent false-positive results.

\section{Nonsyndrome-specific biochemical testing}

Chromogranin A is the diagnostic biomarker of choice for NETs. ${ }^{10,41}$ It has a high sensitivity (53\%-91\%) but low specificity $(<50 \%) \cdot{ }^{10,42,43}$ The most common reasons for false elevations include proton-pump inhibitors, renal insufficiency, adenocarcinomas and severe arterial hypertension..$^{10,44}$

\section{Diagnostic imaging}

There are two general categories of diagnostic imaging modalities that are used in combination for the diagnosis of NETs.

The first modality is standard cross-sectional imaging with computed tomography (CT) or magnetic resonance imaging (MRI). Canadian consensus guidelines recommend that all patients with a suspected NET should receive CTs of the chest, abdomen and pelvis for staging, and consideration of an MRI of the liver or pancreas in cases where further definition is required. ${ }^{7,8}$

The second modality is functional imaging, which takes advantage of the overexpression of somatostatin receptors commonly seen in NETs. Radiolabelled somatostatin analogues are

\begin{tabular}{|c|c|}
\hline Symptom & Percentage of cases \\
\hline \multicolumn{2}{|l|}{ Gastroenteropancreatic } \\
\hline Abdominal pain & $28-79$ \\
\hline Bowel obstruction & $18-24$ \\
\hline Diarrhea & $10-32$ \\
\hline Carcinoid heart disease & $8-19$ \\
\hline Flushing & $4-25$ \\
\hline Gastrointestinal bleed & $4-10$ \\
\hline Incidental & $9-18$ \\
\hline \multicolumn{2}{|l|}{ Bronchopulmonary } \\
\hline Cough & $5-27$ \\
\hline Hemoptysis & $23-32$ \\
\hline Recurrent infection & $41-49$ \\
\hline Incidental & $17-39$ \\
\hline
\end{tabular}

administered intravenously, concentrate in NETs, and the emitted radiation is detected to localize tumours. ${ }^{111}$ Indium (In)labelled pentetreotide is the most commonly used radiotracer in Canada. A recent meta-analysis of molecular imaging methods for NETs reported that ${ }^{111}$ In-labelled pentetreotide somatostatin receptor scintigraphic imaging had a sensitivity of $46 \%-100 \%$ for abdominal NETs, $46 \%-83 \%$ for pancreatic NETs and $71 \%$ for bronchial NETs. ${ }^{45}$

A newer radioisotope, ${ }^{68} \mathrm{Ga}$ (gallium), is a positron emitter that also can be linked to somatostatin analogues and localized with positron emission tomography (PET)/CT imaging. ${ }^{46}$ In a recent prospective single-centre study in the US, 78 patients with NETs underwent imaging with both ${ }^{111}$ In-labelled pentetreotide scans and ${ }^{68} \mathrm{Ga}$-DOTATATE PET/CT. ${ }^{47}$ The sensitivity of ${ }^{68} \mathrm{Ga}$-DOTATATE $\mathrm{PET} / \mathrm{CT}$ compared with imaging using ${ }^{111} \mathrm{In}$-labelled pentetreotide was $96 \%$ (95\% confidence interval $[\mathrm{Cl}], 86 \%-100 \%)$ versus $72 \%(95 \% \mathrm{Cl}, 58 \%-84 \%)$, respectively. Although access to ${ }^{68} \mathrm{Ga}-$ based imaging is currently limited to subspecialty centres in Canada, it is expected to become widely available soon.

It is important to note that somatostatin analogue-based imaging modalities have poor sensitivity in poorly differentiated cancer, because the cells often lack somatostatin receptors. Therefore, poorly differentiated tumours are better imaged with a fluorodeoxyglucose $\left({ }^{18} \mathrm{FDG}\right)$ PET/CT scan, which localizes tumours by uptake of radiolabelled glucose molecules (Figure 2). ${ }^{48}$

\section{Endoscopic imaging}

Endoscopic ultrasonography is the most sensitive test for the diagnosis of pancreatic NETs (sensitivity $82 \%-93 \%$ ). 49,50 Endoscopic ultrasonography is particularly useful for identifying tumours less than $2 \mathrm{~cm}$ in size and for the localization of insulinoma,${ }^{51}$ and often is employed intraoperatively for this purpose.

\section{How are neuroendocrine tumours treated?}

Individualized treatment plans are formulated based on tumour factors such as site, stage, grade, differentiation and symptoms, and patient factors such as age and comorbidities.

\section{Localized disease}

\section{Surgery}

An appropriate oncologic operation focused on margin-negative resection and adequate lymphadenectomy is the only curative treatment modality to date. At the time of resection, it is crucial that the surgeon carefully inspect for synchronous lesions. A retrospective single-centre study involving 691 patients with midgut NETs identified multiple synchronous primary tumours in $22 \%$ of patients, with a range of 2 to 26 tumours. ${ }^{23}$

\section{Adjuvant therapy (chemotherapy after surgery)}

No adjuvant therapy has been proven to improve cure following surgery for NETs. However, based on extrapolation of small cell lung cancer data, consensus guidelines recommend that adjuvant platinum-based chemotherapy be considered for patients with fully resected, poorly differentiated cancers. ${ }^{7,8}$ 


\section{Metastatic disease}

\section{Observation}

In select patients with low-volume, asymptomatic, nonfunctional metastatic disease, observation with expectant management and serial diagnostic imaging is appropriate; historically, many patients remain well without disease progression for years. ${ }^{7,8}$

\section{Somatostatin analogues}

Somatostatin analogues are a cornerstone of the treatment of NETs. Two long-acting somatostatin analogue preparations are available: octreotide long-acting repeatable and lanreotide. Somatostatin analogues were used initially in patients with secretory symptoms only, but two phase 3 RCTs published in 2009 and 2014 showed their antiproliferative effect. $^{52,53}$ In the PROMID trial, 90 patients with well-differentiated metastatic NETs were randomly assigned to either placebo or octreotide. Octreotide long-acting repeatable was associated with improved time to progression (hazard ratio [HR] $0.34,95 \% \mathrm{Cl}$ 0.20-0.59)..$^{52}$ In recently updated survival analyses, no effect was seen on median overall survival ( 84.7 v. $83.7 \mathrm{mo}$ ), but this was felt to be due to the crossover of most patients from placebo to treatment. ${ }^{54}$ Similarly, in the CLARINET trial, 204 patients with moderate to welldifferentiated nonfunctioning NETs were randomly assigned to lanreotide or placebo. Lanreotide was also associated with improved progression-free survival ( $\mathrm{HR} 0.47,95 \% \mathrm{Cl} 0.30-0.73) .{ }^{54}$

Adverse effects of using somatostatin analogues include diarrhea, abdominal pain, nausea, vomiting and hyperglycemia. ${ }^{54}$ Additionally, patients treated with somatostatin analogues have an increased risk of cholelithiasis and biliary sludge development; therefore, prophylactic cholecystectomy should be considered for patients starting long-term treatment with somatostatin analogues. ${ }^{7,855,56}$ However, this recommendation has never been evaluated in a prospective study and is based on retrospective studies that showed high rates of cholelithiasis (52\%-63\%) and modest rates of symptomatic gallbladder disease (7\%-15\%). ${ }^{55,56}$

\section{Surgery}

Surgery plays an important role even in the setting of metastatic disease. Resection of the primary, if located in the small bowel, is usually undertaken to prevent obstruction later, particularly for low-grade tumours with good prognosis. The findings of retrospective population-based studies suggest that this may also improve survival. ${ }^{57,58}$ In the presence of large-volume metastatic disease, surgical cytoreduction can be undertaken to improve control of secretory symptoms that may be hard to control with somatostatin analogue alone; there is also evidence from retrospective studies that this may improve survival. ${ }^{59-61}$

\section{Molecularly targeted biologic therapy}

Everolimus is an oral mammalian target of rapamycin (mTOR) inhibitor that is thought to act by inhibiting cell proliferation, angiogenesis and cell metabolism. Everolimus has proven progression-free survival benefit in well-conducted phase 3 RCTs in gastrointestinal and lung NETs, ${ }^{62-64}$ and pancreatic NETs. ${ }^{65,66}$ In the RADIANT-4 phase III RCT involving 302 patients with advanced progressive nonfunctional lung or gastrointestinal NETs, everolimus was associated with a $52 \%$ reduction in the risk of progression or death (HR 0.48, 95\% Cl 0.35-0.67) compared with placebo. Similarly, in the RADIANT-3 phase 3 RCT involving 410 patients with advanced low- or intermediate-grade pancreatic NETs, everolimus

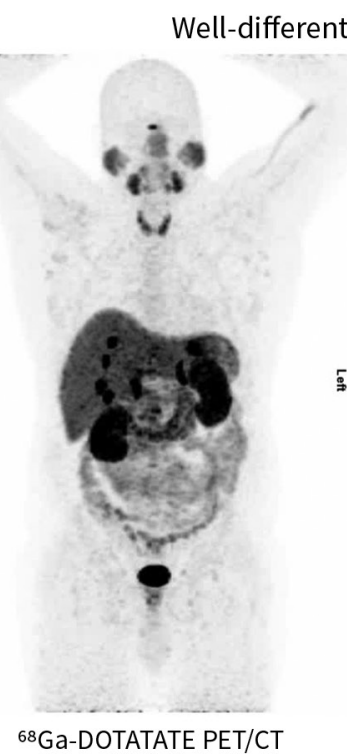

${ }^{68} \mathrm{Ga}$-DOTATATE PET/CT

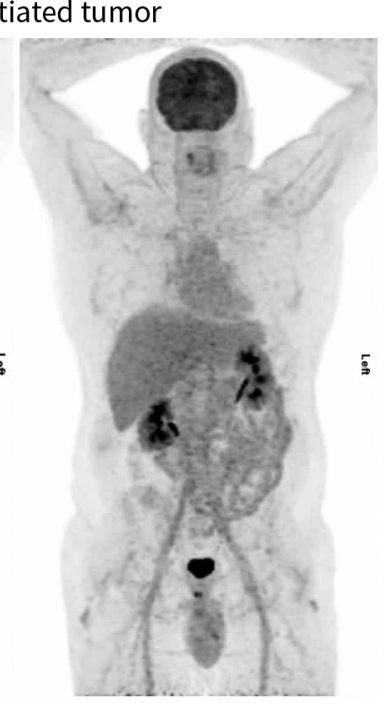

18DG PET/CT

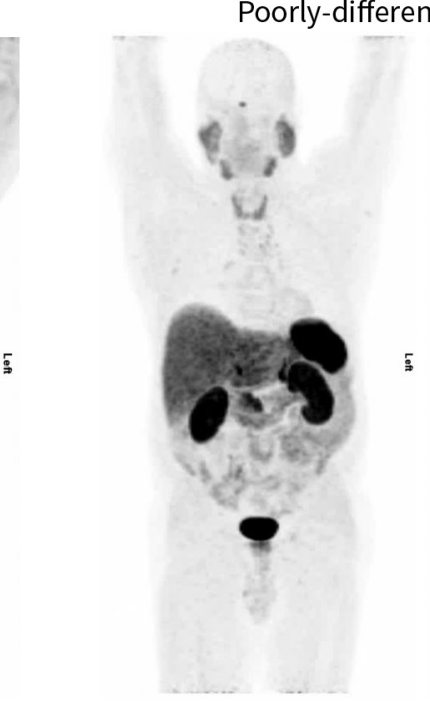

${ }^{68} \mathrm{Ga}$-DOTATATE PET/CT

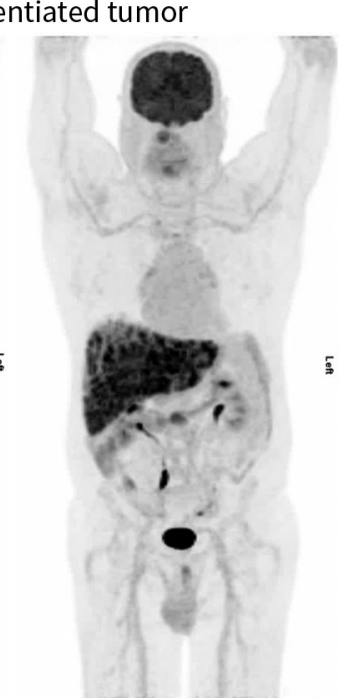

18DG PET/CT

Figure 2: Comparison of ${ }^{68} \mathrm{Ga}$-DOTATATE PET/CT and ${ }^{18} \mathrm{FDG}$ PET/CT for detection of poorly and well-differentiated neuroendocrine tumours. ${ }^{68} \mathrm{Gallium}$ radiolabelled somatostatin analogue $\mathrm{PET} / \mathrm{CT}$ is more sensitive for identifying well-differentiated tumours in which the somatostatin receptor expression is preserved on neuroendocrine cells. ${ }^{18} \mathrm{FDG} \mathrm{PET} / \mathrm{CT}$ is more sensitive for identifying poorly differentiated tumours in which the somatostatin receptor expression has been lost. Please note that the comparison images are from from different patients to illustrate differences in detail by modality based on the differentiation of the tumour. Images provided by Dr. David Chan (Department of Medicine, Sunnybrook Health Sciences Centre, University of Toronto, Toronto, Ont.). FDG = fluorodeoxyglucose, $\mathrm{PET} / \mathrm{CT}$ = positron emission tomography-computed tomography. 
was associated with a $65 \%$ reduction in the risk of progression or death (HR 0.35, 95\% Cl 0.27-0.45) compared with placebo.

Important adverse effects of everolimus include stomatitis, diarrhea, fatigue, pneumonitis, hypophosphatemia, hyperlipidemia and hyperglycemia.

Sunitinib is a multitargeted tyrosine kinase inhibitor that is thought to act by inhibiting angiogenesis. Treatment efficacy for pancreatic NETs was shown in a well-conducted phase 3 RCT involving 171 patients with well-differentiated pancreatic NETs. Compared with placebo, sunitinib was associated with improved progression-free survival (HR $0.42,95 \% \mathrm{Cl} 0.26-0.66)$ and overall survival (HR 0.41, 95\% Cl 0.19-0.89). ${ }^{67}$

Important adverse effects of sunitinib include diarrhea, nausea, vomiting, fatigue, changes to hair colour, hypertension, palmar-plantar erythrodysethesia (hand-foot syndrome) and hypothyroidism.

\section{Peptide receptor radionuclide therapy}

Peptide receptor radionuclide therapy involves attaching a therapeutic radiolabel to a somatostatin analogue that then concentrates in neuroendocrine tissue. The radiolabel, most commonly ${ }^{177}$ Lutetium ( ${ }^{177} \mathrm{Lu}$ ), can then deliver local cytotoxic radiation to the NET. It is administered intravenously every eight weeks for four doses. In the recently reported NETTER-1 phase 3 RCT, compared with placebo, patients who received peptide receptor radionuclide therapy after progression on somatostatin had a significantly increased progression-free survival (median overall survival not yet reached v. $8.4 \mathrm{mo}, p<0.001) .{ }^{68}$

Important adverse effects of peptide receptor radionuclide therapy include renal dysfunction, nausea, vomiting and suppression of bone marrow.

\section{Chemotherapy}

There are no high-quality RCTs guiding chemotherapy treatment for metastatic poorly differentiated cancers. Most evidence is extrapolated from the literature on small cell lung cancer. Similar to small cell lung cancer, there is usually a dramatic and rapid response to chemotherapy, but subsequent relapse is common, with median overall survival of less than 1 year. ${ }^{69,70}$

\section{Unanswered questions}

Several unanswered questions remain. What are the best predictive and prognostic markers for patients with neuroendocrine tumours? What is the optimal follow-up strategy for patients with neuroendocrine tumours? How should the multiple new therapeutic options best be sequenced and/or combined? How do the new therapeutic options affect patient quality of life and survivorship?

\section{Conclusion}

Incidence and prevalence of neuroendocrine tumours are increasing. Awareness of this heterogeneous entity may reduce delay in diagnosis and facilitate expert multidisciplinary care. Treatment options are rapidly expanding; therefore, many patients could have long periods of well-controlled symptoms and a better quality of life.

\section{References}

1. Hallet J, Law CHL, Cukier M, et al. Exploring the rising incidence of neuroendocrine tumors: a population-based analysis of epidemiology, metastatic presentation, and outcomes. Cancer 2015;121:589-97.

2. Canadian Cancer Society's Advisory Committee on Cancer Statistics. Canadian Cancer Statistics 2015. Toronto: Canadian Cancer Society; 2015.

3. Singh S, Granberg D, Wolin E, et al. Patient-reported burden of a neuroendocrine tumor (NET) diagnosis: results from the first global survey of patients with NETs. J Glob Oncol 2016 Oct. 28 [Epub ahead of print]. 10.1200/JG0.2015.002980.

4. Yao JC, Hassan M, Phan A, et al. One hundred years after "carcinoid": epidemiology of and prognostic factors for neuroendocrine tumors in 35,825 cases in the United States. J Clin Oncol 2008;26:3063-72.

5. Pape UF, Berndt U, Müller-Nordhorn J. Prognostic factors of long-term outcome in gastroenteropancreatic neuroendocrine tumors. Endocr Relat Cancer 2008;15: 1083-97.

6. Ter-Minassian M, Chan JA, Hooshmand SM, et al. Clinical presentation, recurrence, and survival in patients with neuroendocrine tumors: results from a prospective institutional database. Endocr Relat Cancer 2013;20:187-96.

7. Singh S, Asa SL, Dey C, et al. Diagnosis and management of gastrointestinal neuroendocrine tumors: an evidence-based Canadian consensus. Cancer Treat Rev 2016;47:32-45.

8. Singh S, Dey C, Kennecke H, et al. Consensus recommendations for the diagnosis and management of pancreatic neuroendocrine tumors: guidelines from a Canadian National Expert Group. Ann Surg Oncol 2015;22:2685-99.

9. Langley K. The neuroendocrine concept today. Ann N Y Acad Sci 1994;733:1-17.

10. Singh S, Law C. Chromogranin A: a sensitive biomarker for the detection and post-treatment monitoring of gastroenteropancreatic neuroendocrine tumors. Expert Rev Gastroenterol Hepatol 2012;6:313-34.

11. Yang X, Yang Y, Li Z, et al. Diagnostic value of circulating chromogranin a for neuroendocrine tumors: a systematic review and meta-analysis. PLoS One 2015;10:e0124884.

12. Oberg K, Modlin IM, De Herder W, et al. Consensus on biomarkers for neuroendocrine tumour disease. Lancet Oncol 2015;16:e435-46.

13. de Herder WW, Hofland LJ, van der Lely AJ, et al. Somatostatin receptors in gastroenteropancreatic neuroendocrine tumours. Endocr Relat Cancer 2003;10:451-8.

14. Oberg K, Kvols L, Caplin M, et al. Consensus report on the use of somatostatin analogs for the management of neuroendocrine tumors of the gastroenteropancreatic system. Ann Oncol 2004;15:966-73.

15. Klimstra DS, Modlin IR, Coppola D, et al. The pathologic classification of neuroendocrine tumors: a review of nomenclature, grading, and staging systems. Pancreas 2010;39:707-12.

16. Nadler A, Cukier M, Rowsell C, et al. Ki-67 is a reliable pathological grading marker for neuroendocrine tumors. Virchows Arch 2013;462:501-5.

17. Jamali M, Chetty R. Predicting prognosis in gastroenteropancreatic neuroendocrine tumors: an overview and the value of Ki-67 immunostaining. Endocr Pathol 2008;19:282-8.

18. Rindi G, Klöppel G, Couvelard A, et al. TNM staging of midgut and hindgut (neuro) endocrine tumors: a consensus proposal including a grading system. Virchows Arch 2007;451:757-62.

19. Travis WB. The concept of pulmonary neuroendocrine tumors. In: Travis WD, Brambilla, E, Muller-Hermelink HK, et al., editors. Pathology and genetics of tumors of the lung, pleura, thymus and heart. Lyon (France): IARC Press; 2004.

20. Kunz PL. Carcinoid and neuroendocrine tumors: building on success. J Clin Oncol 2015;33:1855-63.

21. Stephen E, Byrd DR, Compton CC, editors. AJCC Cancer Staging Manual. 7th ed. New York: Springer; 2011.

22. Modlin IM, Shapiro MD, Kidd M. Siegfried Oberndorfer: origins and perspectives of carcinoid tumors. Hum Pathol 2004;35:1440-51.

23. Strosberg JR, Weber JM, Feldman M, et al. Prognostic validity of the American Joint Committee on Cancer Staging Classification for midgut neuroendocrine tumors. J Clin Oncol 2013;31:420-5.

24. Harpole DH Jr, Feldman JM, Buchanan S, et al. Bronchial carcinoid tumors: a retrospective analysis of 126 patients. Ann Thorac Surg 1992;54:50-4, discussion 54-5.

25. Fink G, Krelbaum T, Yellin A, et al. Pulmonary carcinoid: presentation, diagnosis, and outcome in 142 cases in Israel and review of 640 cases from the literature. Chest 2001;119:1647-51.

26. Hurt R, Bates M. Carcinoid tumors of the bronchus: a 33 year experience. Tho$\operatorname{rax} 1984 ; 39: 617-23$.

27. Kaltsas GA, Besser GM, Grossman AB. The diagnosis and medical management of advanced neuroendocrine tumors. Endocr Rev 2004;25:458-511.

28. Makridis C, Rastad J, Oberg K, et al. Progression of metastases and symptom improvement from laparotomy in midgut carcinoid tumors. World J Surg 1996; 20:900-6, discussion 907. 
29. de Matos LL, Trufelli DC, das Neves-Pereira JC, et al. Cushing's syndrome secondary to bronchopulmonary carcinoid tumor: report of two cases and literature review. Lung Cancer 2006;53:381-6.

30. Liddle GW, Givens JR, Nicholson WE, et al. The Ectopic ACTH Syndrome. Cancer Res 1965;25:1057-61.

31. Salgado LR, Villares Fragoso MCB, Knoepfelmacher M, et al. Ectopic ACTH syndrome: our experience with 25 cases. Eur J Endocrinol 2006;155:725-33.

32. Saha S, Hoda S, Godfrey R, et al. Carcinoid tumors of the gastrointestinal tract: a 44-year experience. South Med J 1989;82:1501-5.

33. Moertel CG, Sauer WG, Dockerty MB, et al. Life history of the carcinoid tumor of the small intestine. Cancer 1961;14:901-12.

34. Onaitis MW, Kirshbom PM, Hayward TZ, et al. Gastrointestinal carcinoids: characterization by site of origin and hormone production. Ann Surg 2000;232:549-56.

35. Pellikka PA, Tajik AJ, Khandheria BK, et al. Carcinoid heart disease. Clinical and echocardiographic spectrum in 74 patients. Circulation 1993;87:1188-96.

36. Bhattacharyya S, Toumpanakis C, Caplin ME, et al. Analysis of 150 patients with carcinoid syndrome seen in a single year at one institution in the first decade of the twenty-first century. Am J Cardiol 2008;101:378-81.

37. Zuetenhorst JM, Bonfrer JMGM, Korse CM, et al. Carcinoid heart disease: the role of urinary 5-hydroxyindoleacetic acid excretion and plasma levels of atrial natriuretic peptide, transforming growth factor-beta and fibroblast growth factor. Cancer 2003;97:1609-15.

38. Kahil ME, Brown H, Fred HL. The carcinoid crisis. Arch Intern Med 1964;114:26-8.

39. Feldman JM, O'Dorisio TM. Role of neuropeptides and serotonin in the diagnosis of carcinoid tumors. Am J Med 1986;81:41-8.

40. Bajetta E, Ferrari L, Martinetti A, et al. Chromogranin A, neuron specific enolase, carcinoembryonic antigen, and hydroxyindole acetic acid evaluation in patients with neuroendocrine tumors. Cancer 1999;86:858-65.

41. Taupenot L, Harper KL, O'Connor DT. The chromogranin-secretogranin family. N Engl J Med 2003;348:1134-49.

42. Nobels FRE, Kwekkeboom DJ, Coopmans W, et al. Chromogranin a as serum marker for neuroendocrine neoplasia: comparison with neuron-specific enolase and the $\alpha$-subunit of glycoprotein hormones. J Clin Endocrinol Metab 1997;82:2622-8.

43. Schürmann G, Raeth $U$, Wiedenmann B, et al. Serum chromogranin A in the diagnosis and follow-up of neuroendocrine tumors of the gastroenteropancreatic tract. World J Surg 1992;16:697-701.

44. Modlin IM, Gustafsson BI, Moss SF, et al. Chromogranin A - biological function and clinical utility in neuroendocrine tumor disease. Ann Surg Oncol 2010;17:2427-43.

45. Koopmans KP, Neels ON, Kema IP, et al. Molecular imaging in neuroendocrine tumors: molecular uptake mechanisms and clinical results. Crit Rev Oncol Hematol 2009;71:199-213.

46. van Essen M, Sundin A, Krenning EP, et al. Neuroendocrine tumours: the role of imaging for diagnosis and therapy. Nat Rev Endocrinol 2014;10:102-14.

47. Deppen SA, Blume J, Bobbey AJ, et al. ${ }^{68} \mathrm{Ga}$-DOTATATE compared with ${ }^{111}$ In-DTPA-octreotide and conventional imaging for pulmonary and gastroenteropancreatic neuroendocrine tumors: a systematic review and meta-analysis. J Nucl Med 2016;57:872-8.

48. Squires MH III, Volkan Adsay N, Schuster DM, et al. Octreoscan versus FDG-PET for neuroendocrine tumor staging: a biological approach. Ann Surg Oncol 2015;22:2295-301.

49. Anderson MA, Carpenter S, Thompson NW, et al. Endoscopic ultrasound is highly accurate and directs management in patients with neuroendocrine tumors of the pancreas. Am J Gastroenterol 2000;95:2271-7.

50. Rösch T, Lightdale CJ, Botet JF, et al. Localization of pancreatic endocrine tumors by endoscopic ultrasonography. N Engl J Med 1992;326:1721-6.

51. Khashab MA, Yong E, Lennon AM, et al. EUS is still superior to multidetector computerized tomography for detection of pancreatic neuroendocrine tumors. Gastrointest Endosc 2011;73:691-6.
52. Rinke A, Müller HH, Schade-Brittinger $\mathrm{C}$, et al. Placebo-controlled, doubleblind, prospective, randomized study on the effect of octreotide LAR in the control of tumor growth in patients with metastatic neuroendocrine midgut tumors: a report from the PROMID study group. J Clin Oncol 2009;27:4656-63.

53. Caplin ME, Pavel M, Ćwikła JB, et al. Lanreotide in metastatic enteropancreatic neuroendocrine tumors. N Engl J Med 2014;371:224-33.

54. Rinke A, Wittenberg M, Schade-Brittinger C, et al. Placebo-controlled, double blind, prospective, randomized study on the effect of octreotide LAR in the control of tumor growth in patients with metastatic neuroendocrine midgut tumors (PROMID): results on long-term survival. Neuroendocrinology 2017;104:26-32.

55. Trendle MC, Moertel CG, Kvols LK. Incidence and morbidity of cholelithiasis in patients receiving chronic octreotide for metastatic carcinoid and malignant islet cell tumors. Cancer 1997;79:830-4.

56. Norlén $\mathrm{O}$, Hessman $\mathrm{O}$, Stålberg P, et al. Prophylactic cholecystectomy in midgut carcinoid patients. World J Surg 2010;34:1361-7.

57. Ahmed A, Turner G, King B, et al. Midgut neuroendocrine tumours with liver metastases: results of the UKINETS study. Endocr Relat Cancer 2009;16:885-94.

58. Hill JS, McPhee JT, McDade TP, et al. Pancreatic neuroendocrine tumors: the impact of surgical resection on survival. Cancer 2009;115:741-51.

59. Glazer ES, Tseng JF, Al-Refaie W, et al. Long-term survival after surgical management of neuroendocrine hepatic metastases. HPB (Oxford) 2010;12:427-33.

60. Mayo SC, de Jong MC, Pulitano C, et al. Surgical management of hepatic neuroendocrine tumor metastasis: results from an international multi-institutional analysis. Ann Surg Oncol 2010;17:3129-36.

61. Sarmiento JM, Heywood G, Rubin J, et al. Surgical treatment of neuroendocrine metastases to the liver: a plea for resection to increase survival. J Am Coll Surg 2003;197:29-37.

62. Yao JC, Phan AT, Chang DZ, et al. Efficacy of RAD001 (everolimus) and octreotide LAR in advanced low- to intermediate-grade neuroendocrine tumors: results of a phase II study. J Clin Oncol 2008;26:4311-8.

63. Pavel ME, Hainsworth JD, Baudin E, et al.; RADIANT-2 Study Group. Everolimus plus octreotide long-acting repeatable for the treatment of advanced neuroendocrine tumours associated with carcinoid syndrome (RADIANT-2): a randomised, placebo-controlled, phase 3 study. Lancet 2011;378:2005-12.

64. Yao JC, Fazio N, Singh S, et al.; RAD001 in Advanced Neuroendocrine Tumours, Fourth Trial (RADIANT-4) Study Group. Everolimus for the treatment of advanced, non-functional neuroendocrine tumours of the lung or gastrointestinal tract (RADIANT-4): a randomised, placebo-controlled, phase 3 study. Lancet 2016; 387:968-77.

65. Yao JC, Lombard-Bohas C, Baudlin E, et al. Daily oral everolimus activity in patients with metastatic pancreatic neuroendocrine tumors after failure of cytotoxic chemotherapy: a phase II trial. J Clin Oncol 2010;28:69-76.

66. Yao JC, Shah MH, Ito T, et al.; RAD001 in Advanced Neuroendocrine Tumors, Third Trial (RADIANT-3) Study Group. Everolimus for advanced pancreatic neuroendocrine tumors. N Engl J Med 2011;364:514-23.

67. Raymond E, Dahan L, Raoul J, et al. Sunitinib malate for the treatment of pancreatic neuroendocrine tumors. N Engl J Med 2011;364:501-13.

68. Strosberg JR, Wolin EM, Chasen B. NETTER-1 phase III: progression-free survival, radiographic response, and preliminary overall survival results in patients with midgut neuroendocrine tumors treated with ${ }^{177} \mathrm{Lu}$-Dotatate [abstract]. J Clin Oncol 2016;34(Suppl 4S):13.

69. Moertel CG, Kvols LK, O'Connell MJ, et al. Treatment of neuroendocrine carcinomas with combined etoposide and cisplatin. Evidence of major therapeutic activity in the anaplastic variants of these neoplasms. Cancer 1991;68:227-32.

70. Sorbye H, Welin S, Langer SW, et al. Predictive and prognostic factors for treatment and survival in 305 patients with advanced gastrointestinal neuroendocrine carcinoma (WHO G3): the NORDIC NEC study. Ann Oncol 2013;24: 152-60.
Competing interests: Calvin Law and Simron Singh received honoraria from Ipsen Canada as members of their advisory boards. David Chan received speaker fees from Ipsen Australia. David Chan and Simron Singh received nonfinancial support from Novartis. Calvin Law received speaker fees and travel support from Amgen Canada and Novartis Oncology, and honoraria from Baxalta, Ipsen Canada and Novartis Oncology as a member of their advisory boards. He also received nonfinancial support from Amgen Canada. Simron Singh received travel support, speaker fees and nonfinancial support from Novartis Oncology, and nonfinancial support from Pfizer. He also received a grant from Novartis and nonfinancial support from Ipsen Canada. No other competing interests were declared.
Affiliations: Departments of Medicine (Raphael, Chan, Singh) and Surgery (Law), Sunnybrook Health Sciences Centre, University of Toronto, Toronto, Ont.

Contributors: All authors contributed substantially to the conception and design of the review. Michael Raphael performed the original literature search and drafted the first version of the manuscript. David Chan, Calvin Law and Simron Singh revised the manuscript critically for important intellectual content. All of the authors approved the final version to be published and agreed to be accountable for all aspects of the work.

This article was solicited and has been peer reviewed.

Correspondence to: Simron Singh, simron.singh@sunnybrook.ca 